\title{
Androgen receptor localisation and turnover in human prostate epithelium treated with the antiandrogen, Casodex
}

\section{A S Waller, R M Sharrard, P Berthon and N J Maitland}

\author{
Yorkshire Cancer Research, Department of Biology, University of York, \\ York YO10 5YW, UK \\ (Requests for offprints should be addressed to N J Maitland; Email: njm9@york.ac.uk) \\ (P Berthon is now at CeRePP, Genopole 4, rue Pierre Fontaine, 91000 Evry, France)
}

\begin{abstract}
In vitro models of normal and malignant human prostate are currently limited to a few well established cell lines that, with a single exception $(\mathrm{LNCaP})$, fail to express the androgen receptor (AR) - a common characteristic of prostatic epithelium grown in culture. To investigate the molecular mechanism of action of the non-steroidal antiandrogen Casodex (bicalutamide) against wildtype AR, we have established a transient AR expression model in non-tumorigenic prostate cells of both epithelial and mesenchymal origin. In this
\end{abstract}

model, both dihydrotestosterone and Casodex can effectively transport the AR protein into the nucleus of prostate cells. Whereas the natural ligand, dihydrotestosterone, stabilises the receptor, the AR is rapidly degraded at a nuclear location when the transfected cells are treated with Casodex. In contrast, whereas the mutant $\mathrm{AR}$ in the $\mathrm{LNCaP}$ line is also degraded on Casodex treatment over the same time period, its intracellular targeting is defective.

Fournal of Molecular Endocrinology (2000) 24, 339-351

\section{INTRODUCTION}

Metastatic carcinoma of the prostate is a common and potentially life threatening disease that can be effectively treated by administration of antiandrogen drugs. These drugs, of either steroidal or non-steroidal structure (Fig. 1), bind to the androgen receptor (AR) protein in competition with androgens, and block the ability of the AR to transactivate androgen-responsive genes (Teutsch et al. 1994, Kuil \& Mulder 1994, Kuil et al. 1995). Such therapy has been shown to result in the remission of androgen-dependent tumours in $80 \%$ of patients for an average duration of 3 years (Montie 1996, Prostate Cancer Trialists' Collaborative Group 1996). As androgen-regulated gene expression is essential for maintenance of normal prostatic function, blocking of the AR by either surgical or chemical castration results in loss of prostatic tissue, probably by an apoptotic mechanism (Isaacs et al. 1994, Westin et al. 1993, 1995). However, clones of tumour cells that are resistant to the hormone withdrawal treatment, and may possess a greater malignant potential than the original tumour eventually arise within the patients, probably as a result of mutations in the AR gene or in related genes from the response pathway (Culigj et al. 1993a,b, Suzuki et al. 1993, Gaddipati et al. 1994, Elo et al. 1995, Taplin et al. 1995, Visakorpi et al. 1995, Yeh \& Chang 1996, Koivisto et al. 1998).

The AR is a ligand-activated transcription factor of molecular mass $105 \mathrm{kDa}$ composed, like most steroid receptors, of a hormone-binding C-terminal domain, a DNA-binding domain and a transactivation domain (reviewed by Sultan et al. (1993)). The AR is known to exist as a monomer in the cytoplasm of responsive cells, sequestered in a complex with heat-shock proteins (HSPs). On administration and binding of androgens, the AR changes conformation, and the HSPs are released (Veldscholte et al. 1992b). Phosphorylation (Kuiper \& Brinkmann 1995), dimerisation (Wong et al. 1993) and AR translocation into the nucleus can then occur, followed by binding to the hormone response element upstream of AR-regulated genes, resulting in transactivation.

The study of AR interactions at the molecular level in normal prostate has been restricted by the downregulation of $\mathrm{AR}$ expression in almost all 
RECEPTOR DEGRADATION

\section{ANDROGEN/ESTROGEN RECEPTOR LIGAND}

1. $17 \beta$-estradiol

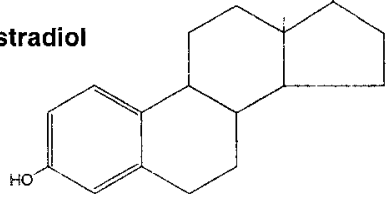

2. ICi 164,384<smiles>CCCCC1Cc2cc(O)ccc2C2CCC3C(O)CC[C@@H]3C12</smiles>

3. Dihydrotestosterone<smiles>CCOC(=O)OC1CCC2CCCC2C2CC[C@H]3CC(=O)CCC3C12</smiles>

4. Casodex (bicalutamide)<smiles>Fc1ccccc1</smiles><smiles></smiles><smiles>CC(C)(O)N1CCC(F)(F)CC1</smiles>

5. Hyaroxyflutamide

\section{RECEPTOR} BINDING

YES

YES

YES

YES

YES

\section{NUCLEAR}

TRANSLOCATION

YES

NO

YES

YES

NO

YES

(Not with mutant AR)

YES

NO

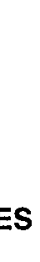

(1)

FIGURE 1. Structures of steroidal and non-steroidal antiandrogen drugs. in vitro cultures of prostate cells within a few weeks of establishment. This downregulation appears to be at the transcriptional level (Hayward et al. 1995 and our unpublished observations), and only transfection of the cells with an AR cDNA can restore wild-type $\mathrm{AR}$ protein to a measurable level (Yuan et al. 1993). Accordingly, most studies of antiandrogen drug action have been carried out in the LNCaP prostate cancer cell line, which does continue to express AR protein. This cell line was developed from a metastatic deposit in the lymph nodes of a patient after both chemotherapy and radiotherapy, and has a mutant $\mathrm{AR}$ with a $\mathrm{Thr} \rightarrow \mathrm{Ala}$ change at amino acid 877 (Veldscholte et al. 1990). The growth of cells expressing the mutant $\mathrm{AR}_{877}$ is stimulated by androgen treatment, but the cells also respond positively to oestrogen, progesterone and even some antiandrogens (Veldscholte et al. 1990, Schuurmans et al. 1991). However, the antiandrogen biculatamide (Casodex; AstraZeneca,
Macclesfield) was demonstrated to behave as an AR antagonist even towards the 877 mutant in LNCaP (Veldscholte et al. 1992a, 1994). Unlike other AR therapeutic agents, Casodex was shown to inhibit the growth of LNCaP cells, and did not activate the $\mathrm{AR}_{877}$ mutant in a HeLa cell co-transfection experiment with an androgen-responsive reporter gene. Casodex also failed to induce dissociation of HSPs from $\mathrm{AR}_{877}$ in LNCaP cells (Veldscholte et al. 1994) - a prerequisite for successful nuclear translocation of the activated AR. Limited proteolytic digestion of AR (produced by in vitro translation) showed different cleavage patterns in the presence of androgens and various antiandrogens, providing evidence of ligand-induced conformational changes, which were maintained with the $\mathrm{AR}_{877}$ mutant only in the presence of Casodex (Kuil \& Mulder 1994, 1995, Kallio et al. 1994). Different androgenic ligands were also shown, in a rat model, to affect receptor stability and turnover (Zhou et al. 1995). 
No studies have yet used a wild-type AR protein (the natural target for antiandrogens in vivo) in human prostate epithelial or fibroblast-derived models to examine the effects of antiandrogens. We have developed a model in which enhanced transient expression of a wild-type AR can be achieved in SV40-immortalised epithelial and fibroblast cultures derived from non-tumorigenic human prostates (Cussenot et al. 1991, Berthon et al. 1995) in order to study regulation of wild-type $\mathrm{AR}$ at the molecular level after exposure to androgens and the antiandrogen Casodex. We believe that this model more accurately reflects the in vivo situation compared with the $\mathrm{LNCaP}$ model. Treatment of the cells in the transient AR model with both androgens and antiandrogens results in correct nuclear targeting of the AR (not observed in $\mathrm{LNCaP}$ ) and an accelerated turnover of $\mathrm{AR}$ protein at discrete locations within the cell nucleus. We propose that this model demonstrates both the correct conformational changes in the AR (Kuil \& Mulder 1994, Kallio et al. 1994) and downstream responses to antiandrogens.

\section{MATERIALS AND METHODS}

\section{Expression vectors}

The human androgen receptor cDNA was kindly provided by Prof. Liao (University of Chicago). It was transferred into the intermediate vector p'T7Blue (Novagen, Madison, WI, USA) via PCR amplification of the $5^{\prime}$ region of the AR incorporating a Not1 site in front of the ATG and modifying the ATG to include the Kozak sequence (Kozak 1989). The full AR cDNA was reconstructed using an internal Nar1 site and BamH1 at the $3^{\prime}$ end of the cDNA from the original clone. This was then ligated into $\mathrm{pCEP} 4$ vector (Invitrogen, Groningen, The Netherlands) utilising the Not1 and BamH1 sites. The cDNA was then completely sequenced to ensure wild-type authenticity. As a transfection control we used pCEP4.CAT (Invitrogen) plasmid, which contains the bacterial chloramphenicol acetyl transferase (CAT) gene under the control of the cytomegalovirus promoter.

\section{Cell culture}

LNCaP.FGC cells were obtained from the American Tissue Culture Collection (catalogue number CRL1740). The immortalised prostatic epithelial cells PNT1A have previously been described by Cussenot et al. (1991). The prostatic fibroblast cell line pf1SV1 was generated and characterised recently by Berthon et al. (1995). All cell lines were maintained in R10 (RPMI with 10\% decomplemented fetal bovine serum (FBS), $2 \mathrm{mM}$ glutamine and $10 \mathrm{mM}$ Hepes (Life Technologies)) at $37{ }^{\circ} \mathrm{C}, 5 \% \mathrm{CO}_{2}$ with media changes twice weekly. Charcoal-stripped medium (R10dcc) was obtained by twice-repeated incubations of FBS with $5 \%$ activated charcoal (Sigma) for $30 \mathrm{~min}$ at $50{ }^{\circ} \mathrm{C}$ followed by $0 \cdot 2 \mu \mathrm{m}$ filtration.

\section{Transfection of prostate cells}

To carry out the transient assay, transfection conditions for the various prostate cell lines were optimised with a number of commercial liposomebased products. $\mathrm{LNCaP}$ cells were best transfected with Lipofectin (Ruokonen et al. 1996), but PNT1A- and pf1SV1-immortalised normal prostate cells demonstrated transfection efficiencies that varied over a tenfold range but were optimal with LipofectAmine (Life Technologies, Paisley, UK; catalogue numbers 18292-011 and 18324-012, used according to the manufacturer's instructions). Approximately $25 \%$ of each cell type expressed the recombinant $\mathrm{AR}$ or CAT gene constructs, as assessed by staining with monoclonal antibodies against the AR (Novocastra, Newcastle upon Tyne, UK; see below) or CAT (Boehringer, Roche Diagnostics, Lewes, UK) proteins.

Cells were grown to $80 \%$ confluency in six well plates or on poly-L-lysine-treated slides for immunofluorescence, washed twice in phosphate-buffered saline (PBS) and incubated for $6 \mathrm{~h}$ at $37^{\circ} \mathrm{C}$ with $1 \mathrm{ml}$ liposome-DNA solution $(10 \mu \mathrm{l}$ of either Lipofectin or LipofectAmine and $2 \mu \mathrm{g}$ Qiagenpurified plasmid DNA in Opti-MEM (Life Technologies). For RNA preparation, $10^{6}$ cells were transfected using Lipofectin (Life Technologies). After transfection, cells were again washed twice in PBS and allowed to recover overnight in R10. Medium was replaced the next morning with fresh R10 or R10dcc for androgen-negative controls. Treatment of the cells was carried out in R10 supplemented with $10^{-6} \mathrm{M}$ dihydrotestosterone (DHT), hydroxyflutamide or Casodex (solubilised in ethanol). Cells were harvested for RNA and protein or fixed for immunofluorescence up to $72 \mathrm{~h}$ after transfection, although the cultures were stable up to 5 days after transfection.

\section{Androgen-binding assays in transfected cells}

To verify that the manipulated AR gene had wildtype activity, an equilibrium androgen-binding assay was carried out on cell extracts of pCEP4.AR and pCEP4.CAT-transfected cells at $24-48 \mathrm{~h}$ after transfection. The binding assay was carried out with whole cell extracts essentially as described by Zhou et al. (1995), except that the synthetic 
androgen mibolerone $\left({ }^{3} \mathrm{H}\right.$-labelled and unlabelled competitor both obtained from New England Nuclear, Hounslow, UK, product numbers NET919 and NLP-024 respectively) were used. Scatchard plots were produced for each binding assay.

(a)

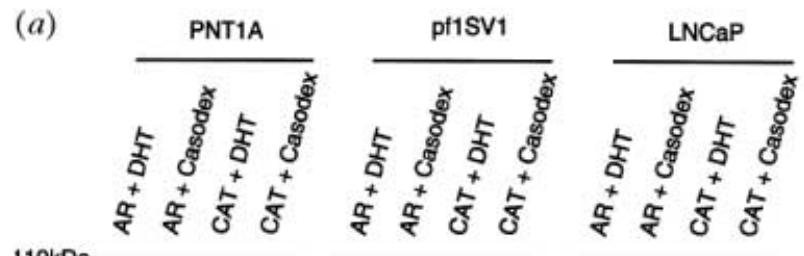

$110 \mathrm{kDa}$
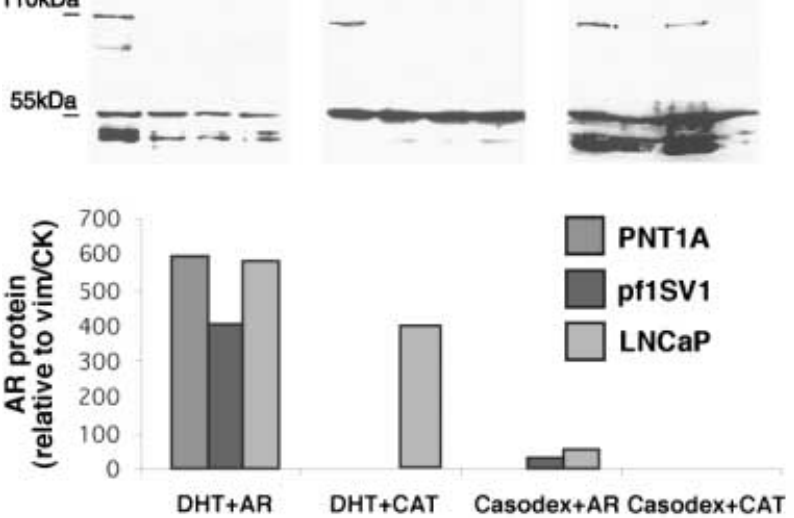

(c)

$144 \mathrm{kDa}$
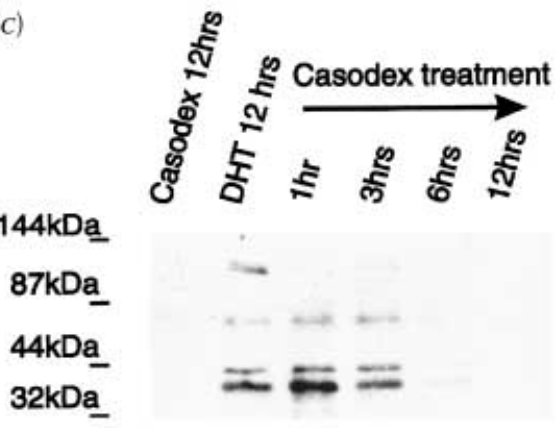

AR

$44 \mathrm{kDa}$

$32 \mathrm{kDa}$

$55 \mathrm{kDa}$

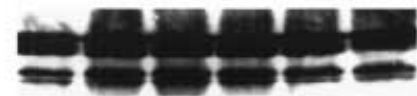

Vimentin

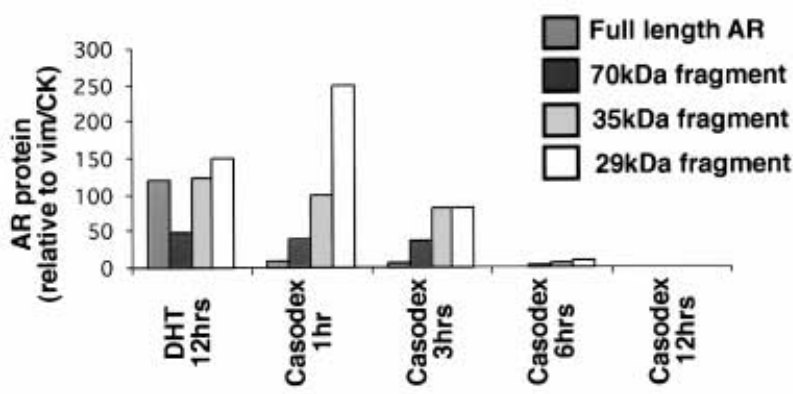

Fournal of Molecular Endocrinology (2000) 24, 339-351

\section{Cell viability measurements with DAPI}

To measure cell viability, the ability of inviable cells in a living tissue culture to incorporate $4^{\prime}, 6-$ diamidino-2-phenylindole (DAPI) was exploited.

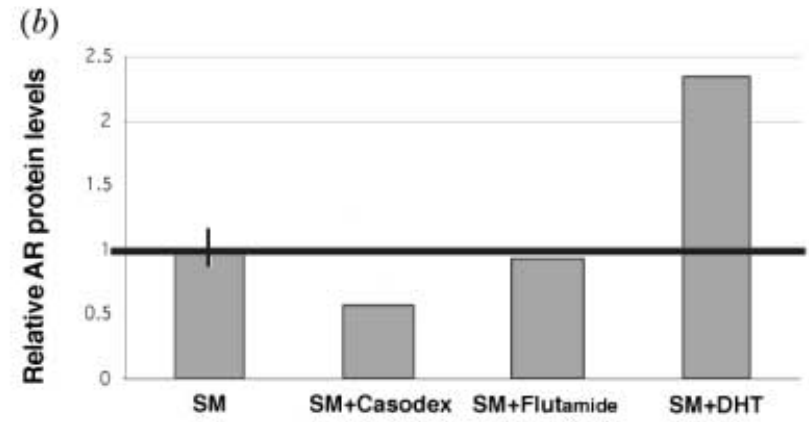

(d)

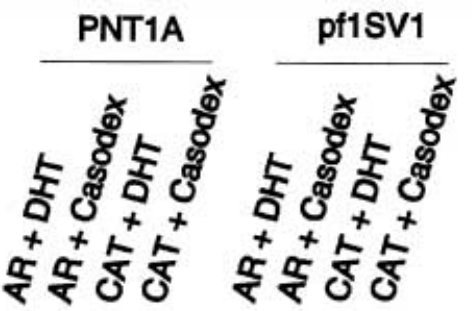

AR $2.9 \mathrm{~kb}$

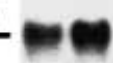

$7.46 \mathrm{~kb}$

$4.40 \mathrm{~kb}$

$-2.37 \mathrm{~kb}$

$-1.35 \mathrm{~kb}$

GAPDH 1.3kb 
The stock DAPI was prepared at $0.5 \mathrm{mg} / \mathrm{ml}$ in PBS. This was further diluted $1: 2000$ in normal growth medium and added to viable cell cultures for $15 \mathrm{~min}$. Excess DAPI was washed off and the cells were viewed under phase and ultraviolet illumination with a Nikon Eclipse inverted microscope $(20 \times$ phase objective) using an appropriate filter. Images of the living cells were captured using a Neotech frame grabber/VHS video camera linked to a Macintosh computer. After image capture, the cultures were washed in PBS and incubated with Annexin V-Alexa568 (Boeringer, catalogue number 1985485, used according to the manufacturer's procedure) to identify apoptotic cells (Vermes et al. 1995) and the fluorescent images again captured.

\section{Western blotting}

Cells were washed twice in ice cold PBS and then lysed on ice in $1 \times$ SDS sample buffer $(50 \mathrm{mM}$ Tris-HCl pH 6.8, 10\% $\beta$-mercaptoethanol, $2 \%$ SDS, $0 \cdot 1 \%$ bromophenol blue, $10 \%$ glycerol, $100 \mu \mathrm{g} / \mathrm{ml}$ phenylmethylsulphonyl fluoride, $1 \mu \mathrm{g} / \mathrm{ml}$ pepstatin A, $1 \mu \mathrm{g} / \mathrm{ml} \mathrm{E64).} \mathrm{The} \mathrm{lysate} \mathrm{was} \mathrm{immedi-}$ ately heated to $96{ }^{\circ} \mathrm{C}$ for $20 \mathrm{~min}$ followed by sonication on ice and centrifugation at $10000 \boldsymbol{g}$ for $10 \mathrm{~min}$ at room temperature.

The lysate was then transferred to a fresh Eppendorf tube and heated to $96{ }^{\circ} \mathrm{C}$ for a further 5 min before loading on a $7 \cdot 5 \%$ SDS polyacrylamide gel and submission to electrophoresis according to Laemmli (1970). After electrophoresis, the gels were soaked for $1 \mathrm{~h}$ in transfer buffer $(39 \mathrm{mM}$ glycine, $48 \mathrm{mM}$ Tris base, $0.037 \%$ SDS and $20 \%$ methanol, final $\mathrm{pH} 8 \cdot 3$ ). Proteins were transferred by electroblotting on to Hybond ECL (Amersham International, Bucks, UK). Membranes were washed for $20 \mathrm{~min}$ in PBS and blocked for $1 \mathrm{~h}$ in PBS, 5\% Marvel at room temperature. Before addition of the primary antibody, membranes were rinsed and then washed for $1 \times 10 \mathrm{~min}$ and $2 \times 5$ min in PBS. AR monoclonal antibody $2 \mathrm{~F} 12$ (Novocastra) was diluted $1 / 60$ in blocking solution and incubated on the membrane overnight at room temperature. Membranes were washed as above and the secondary antimouse HRP-linked antibody (Amersham) added at a dilution of $1 / 1000$ in blocking solution for $2 \mathrm{~h}$ at room temperature. After rinsing with PBS, blots were washed for a period of $1 \mathrm{~h}$ with several changes of PBS. Protein expression was visualised using the enhanced chemiluminescence (ECL detection kit; Amersham). Loading controls were CK8 (clone M20; Sigma, Poole, Dorset) for epithelial lines and vimentin (V-4630, Sigma) for pf1SV1.

\section{Northern blotting}

Cells were washed twice with sterile PBS and total RNA prepared using TriZol according to the

FIGURE 2. Effects of Casodex on AR expression in prostate cells. (a) AR protein degradation after Casodex treatment. Cells were transfected with either pCEP4.AR (first two lanes in each panel) or pCEP4.CAT (final two lanes in each panel) as described in Materials and Methods, and allowed to recover overnight in R10 medium. The medium was replaced with R10, followed by a further change after 48-72 h when the R10 was supplemented with either DHT $\left(10^{-6} \mathrm{M}\right)$ or Casodex $\left(10^{-6} \mathrm{M}\right)$ for $12 \mathrm{~h}$. Protein extracts were prepared and the AR content of the cells was measured by western blot (top panel). Expression of cytokeratin 8 for LNCaP and PNT1A, or vimentin for pf1SV1 (bottom panels) was subsequently detected by stripping and reprobing the same blots. Molecular mass markers are shown to the left of each panel, and the intact AR is present at approx $110 \mathrm{kDa}$. The relative levels of AR protein (shown in the lower panel) were calculated by scanning densitometry with NIH Image $1 \cdot 61$, and a ratio relative to the loading control (cytokeratin 8 for epithelial cells and vimentin for pf1SV1) was produced. (b) Relative stabilisation of AR in stripped medium containing steroid supplements. Twenty-four hours after transfection with pCEP4.AR, PNT1A cells were washed twice with R10dcc medium and cultured in fresh R10dcc medium for $1 \mathrm{~h}$. At this point DHT, hydroxyflutamide or Casodex was added to a final concentration of $10^{-6} \mathrm{M}$. Six hours later the adherent cells were washed and harvested for western blot analysis. The results of densitometry of the western blot are shown in the histogram, normalised to a value of 1 for AR transfected cells maintained in R10dcc (the errors are shown in the first bar by the narrow bar). (c) Time course of AR loss after treatment of pf1SV1 cells with Casodex. Two days after transfection with pCEP4.AR, pf1SV1 cells were treated with Casodex $\left(10^{-6} \mathrm{M}\right)($ lane 1$)$ or DHT $\left(10^{-6} \mathrm{M}\right)$ (remaining lanes) for $12 \mathrm{~h}$. All cells were then washed with PBS and harvested for protein and western blotting (lanes 1 and 2) either immediately or after treatment with Casodex (10 ${ }^{-6} \mathrm{M}$ in R10 medium) for $1 \mathrm{~h}$ (lane 3 ), $3 \mathrm{~h}($ lane 4$)$, $6 \mathrm{~h}$ (lane 5) and $12 \mathrm{~h}$ (lane 6). All protein samples were western blotted for AR protein detection (top panel) and stripped and reprobed for vimentin as before (lower panel). Quantification (shown in the bottom panel) was carried out as in $(a) .(d)$ Transcription of AR in Casodex-treated cells. One million PNT1A and pf1SV1 cells were transfected with $2 \mu \mathrm{g}$ either pCEP4.CAT or pCEP4.AR and treated with $10^{-6} \mathrm{M}$ DHT or $10^{-6} \mathrm{M}$ Casodex as indicated for $12 \mathrm{~h}$. Total cell RNA was extracted and analysed by Northern blotting as described in Materials and Methods. The blots were probed sequentially for AR $(2 \cdot 9 \mathrm{~kb}$ mRNA in the top panel) and GAPDH $(1 \cdot 3 \mathrm{~kb}$ mRNA in the bottom panel). Molecular sizing (not shown) was by comparison with standard RNA markers (Life Technologies). 
manufacturer's instructions (Life Technologies). The RNA was quantified on a standard agarose gel before electrophoresis of $10 \mu \mathrm{g}$ aliquots in a $1 \%$ agarose gel containing $2 \cdot 2 \mathrm{M}$ formaldehyde. A capillary blot with $20 \times \mathrm{SSC}$ was used to transfer the separated RNA on to HybondN+ (Amersham). RNA was immobilised with alkali fixation $(0 \cdot 05 \mathrm{M}$ $\mathrm{NaOH}$ ) for $5 \mathrm{~min}$. Membranes were prehybridised with Rapid Hyb (Amersham) containing $200 \mu \mathrm{g}$ denatured sonicated salmon sperm $\mathrm{DNA} / \mathrm{ml}$ at $65{ }^{\circ} \mathrm{C}$ for $20 \mathrm{~min}$. All AR probes were PCRgenerated from pCEP4.AR using the following primers: forward 5'-ACCGTCAGATCTCTAGA AGC-3' (from the CMV promoter in pCEP4), reverse $5^{\prime}$-CACTGCCTTACACAACTCCT-3' (from the AR gene). The $\mathrm{PCR}$ product was Qiagen-purified and radiolabelled with $\left[{ }^{32} \mathrm{P}\right] \mathrm{dATP}$ in a second PCR reaction using only the reverse primer. The final single-stranded antisense probe was purified by chromatography in a NAP5 column (Pharmacia). Blots were hybridised at $65{ }^{\circ} \mathrm{C}$ overnight and then washed by incubation in $2 \times \mathrm{SSC}, 0 \cdot 1 \% \mathrm{SDS}$ at room temperature for $2 \times 10 \mathrm{~min}$, followed by an incubation at $65{ }^{\circ} \mathrm{C}$ for $15 \mathrm{~min}$ in $1 \times \mathrm{SSC}, 0 \cdot 1 \% \mathrm{SDS}$ and finally two washes for $10 \mathrm{~min}$ at $65^{\circ} \mathrm{C}$ in $0 \cdot 1 \times \mathrm{SSC}$, $0 \cdot 1 \%$ SDS. AR mRNA expression was visualised by autoradiography. The expression of the housekeeping gene glyceraldehyde-3-phosphatedehydrogenase (GAPDH) mRNA served as a loading control (the primers used to generate the antisense probe, exactly as described for the AR probe, were:

forward 5'-AAGGTGAAGGTCGGAGTC AACG-3', reverse 5'-CGGTTTTCCCAGTAGTAGAG ACGG-3').

\section{Immunofluorescence}

Slides were washed twice in PBS and then fixed in methanol/acetone $(2: 1)$ for $5 \mathrm{~min}$, washed for $3 \times 5 \mathrm{~min}$ in PBS and air dried. Cells were rehydrated with a drop of PBS, $0 \cdot 1 \%$ bovine serum albumin (BSA) for $10 \mathrm{~min}$ and blocked for $30 \mathrm{~min}$ according to the ABC kit (Vector Laboratories, Burlingame, CA, USA), followed by washing for $2 \times 10$ min with PBS, $0 \cdot 1 \% \mathrm{BSA}$ and incubation in a humidified chamber at room temperature overnight with antihuman AR antibody clone $2 \mathrm{~F} 12$ (Novocastra) at a dilution of $1 / 10$ in PBS, $1 \%$ BSA. For cytokeratin 8 (clone M20, Sigma) and vimentin (V-4630 Sigma) controls, dilutions were 1/1000 and $1 / 10$ respectively in PBS, 3\% BSA for $1 \mathrm{~h}$. The primary antibodies were washed off with two incubations for 10 min with PBS, $0 \cdot 1 \% \mathrm{BSA}$ and the secondary anti-mouse FITC conjugated antibody (Dako) was added for $2 \mathrm{~h}$ at a dilution of $1 / 20$ in PBS, 3\% BSA. Slides were washed four times in
PBS, $0 \cdot 1 \%$ BSA and mounted in Citifluor (Agar Scientific, Stansted, Essex, UK).

\section{RESULTS}

\section{Maximising efficiency of AR expression}

To prevent potential transcriptional silencing of the transfected AR gene, a modified AR cDNA was constructed. First, the $5^{\prime}$ untranslated sequence, which has been shown to encode a translational silencer sequence in mouse, was deleted and the non-optimal Kozak consensus sequence (Kozak 1989) surrounding the ATG start codon was modified. These modifications increased translational efficiency by up to fourfold in human cells. Secondly, the entire construct was sequenced and inserted into the mammalian expression vector pCEP4 (Invitrogen), which permits episomal replication and maintenance of the transfected gene.

Transient transfection was optimised for both the PNT1A and pf1SV1 cell lines with wild-type AR cDNA in pCEP4, using different combinations of commercially available liposomes (see Materials and Methods). This produced levels of expression of AR protein approximately equal to those of the $\mathrm{AR}_{877}$ mutant in $\mathrm{LNCaP}$, as estimated from western blotting (Fig. 2). As an average of $25 \%$ of PNT1 cells in each culture had been transfected, we estimate that the amounts of AR per cell are fourfold greater in the transient system than in the untransfected LNCaP cells - a conclusion borne out by exposure times for photomicroscopy of the immunofluorescence detection of AR (see below).

To verify that the translationally optimised AR cDNA constructs were producing active protein, an equilibrium steroid binding assay using the synthetic androgen mibolerone was carried out, essentially as described by Zhou et al. (1995). The slopes of the resultant Scatchard plots were virtually identical for the AR-transfected cells and for the mutant receptor in $\mathrm{LNCaP}$, indicating that the affinity of the receptor for steroid was unaffected by the AR cDNA manipulation. Equilibrium binding affinity constants were within the range $0 \cdot 25-0 \cdot 4 \mathrm{nM}$ as described by Zhou et al. (1995). The numbers of active receptors/cell as calculated from the same plot were more variable, but were two- to threefold greater in the transfected cells than in $\mathrm{LNCaP}$ cells, in agreement with the AR protein levels determined by western blotting.

AR protein was readily detectable in a western blot within $24 \mathrm{~h}$ of transfection (Fig. $2 a$ : leftmost lane in each panel shows amounts after $48 \mathrm{~h}$ ). However, after $12 \mathrm{~h}$ of treatment with $10^{-6} \mathrm{M}$ Casodex, the AR was undetectable in both the wild-type and mutant AR-expressing cells (Fig. 2a, 


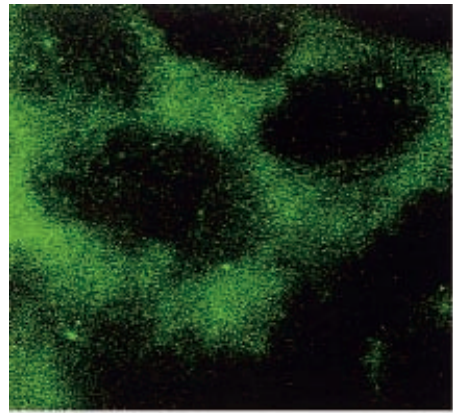

(a)

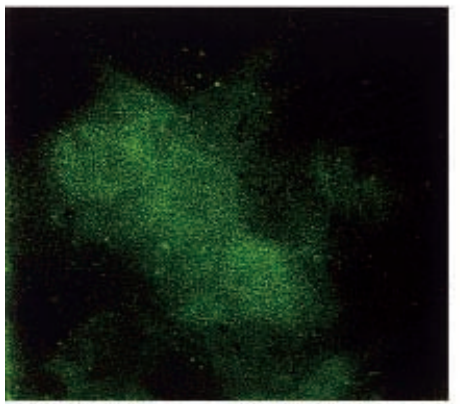

(b)

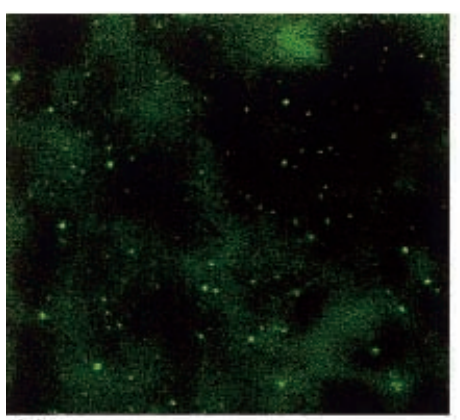

(c)

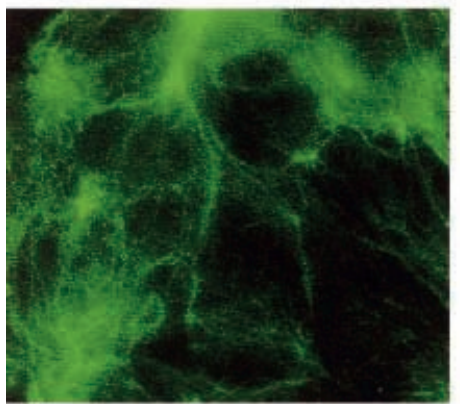

(d)

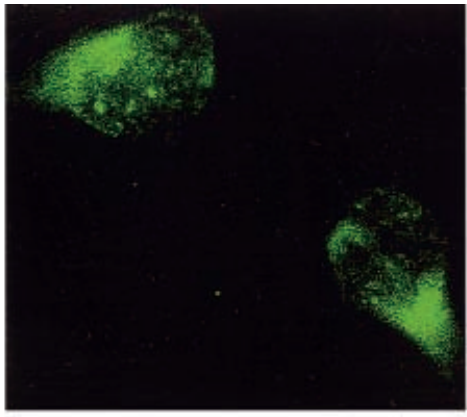

(e)

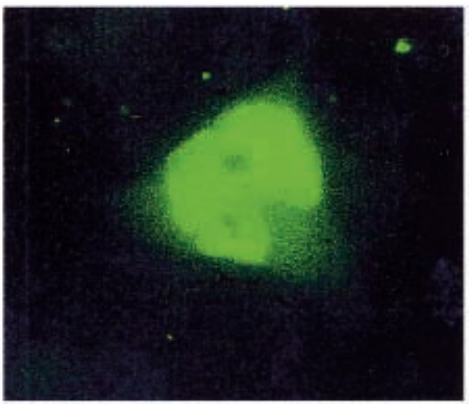

(f)

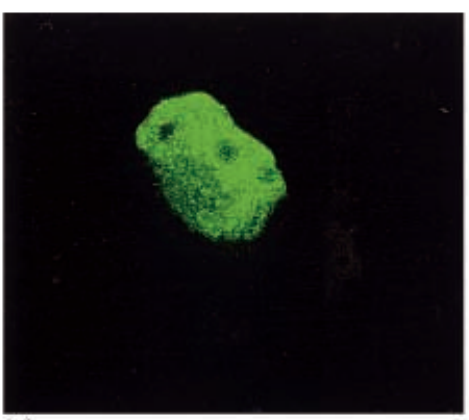

(g)

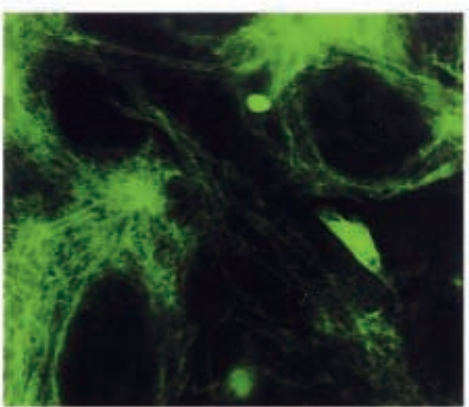

(h)

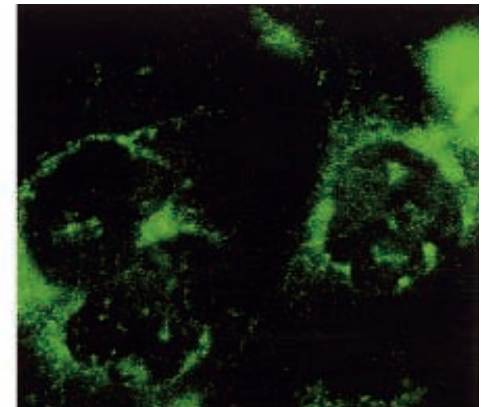

(i)

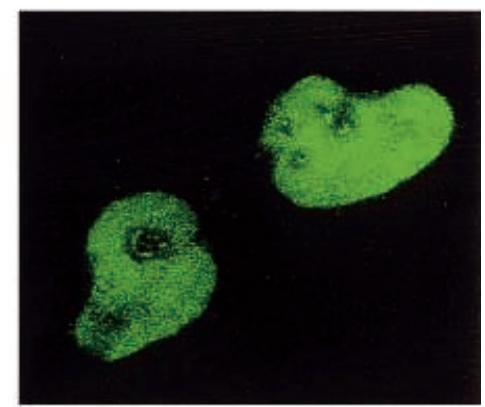

(j)

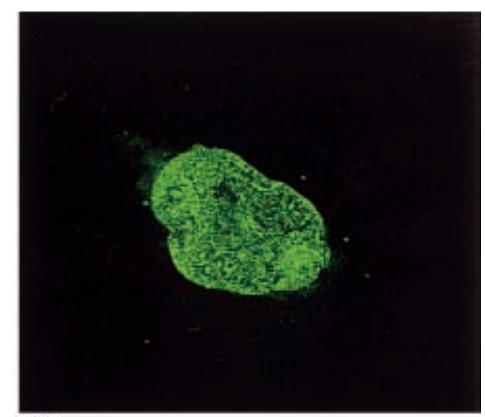

(k)

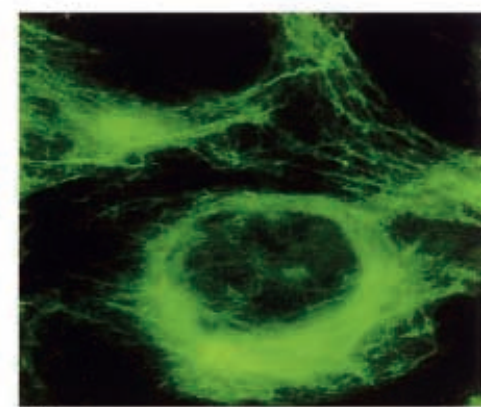

(I)

FIGURE 3. Detection of AR protein expression by immunofluorescence. Prostate cells grown on sterile glass microscope slides were transfected with pCEP4.AR as described previously, and treated for $48 \mathrm{~h}$ in $\mathrm{R} 10 \mathrm{dcc}$ medium $(a, e, i)$. Duplicates were then treated for $6 \mathrm{~h}$ with $10^{-6} \mathrm{M} \mathrm{DHT}(b, f, j)$ or $10^{-6} \mathrm{M}$ Casodex $(c, g$, $k)$. Further cultures, maintained in R10 after transfection, were stained with monoclonal antibodies against cytokeratin $8(d, h)$ or vimentin $(l)$. A threefold longer exposure time was required for photography at $400 \times$ magnification of the positive $\mathrm{AR}$ stain in $\mathrm{LNCaP}$ (indicated by the greater overall background fluorescence). 
second lane). Comparisons of the relative stabilisation of transfected AR with DHT, Casodex and hydroxyflutamide in stripped (R10dcc) medium in a number of prostatic epithelial cells confirmed both the AR binding activity in the transfected cells and the specificity of Casodex action. For all the androgens and antiandrogens, the optimal concentrations were obtained by variation between $10^{-3} \mathrm{M}$ and $10^{-10} \mathrm{M}$ in preliminary experiments. A constant $1 \mu \mathrm{M}$ concentration for both agonists and antagonists was selected, as it showed optimal stabilisation and degradative responses in the model system (Waller 1998). In other systems the concentration of DHT required is somewhat lower (nM range) (Zhou et al. 1995). However, addition of $10^{-6} \mathrm{M}$ DHT stabilised the AR, relative (2$2 \cdot 5$-fold) to both R10dcc alone and R10dcc+ hydroxyflutamide, whereas Casodex reduced the levels of AR to between 10 and $50 \%$ of the original values within $6 \mathrm{~h}$ of its addition to the growth medium (Fig. 2b). The effects of Casodex were also observed in treated LNCaP cells, but the magnitude was considerably reduced. Maintenance of the $\mathrm{LNCaP}$ cells in $\mathrm{R} 10+\mathrm{dcc}$ also led (over a longer period) to a loss of cell viability, as reported by Saeed et al. (1997). Control transfections of PNT1, pf1SV1 and LNCaP cells with the pCEP4.CAT gene construct showed endogenous $\mathrm{AR}$ expression in only the $\mathrm{LNCaP}$ cells.

A time course of Casodex effects (shown in Fig. $2 c$ for pf1SV1) in all the cell types showed a progressive accumulation of AR breakdown products, implying a specific pattern of proteolysis. Random degradation of cell proteins and western loadings were controlled by reprobing the filters with antibodies against cytokeratin 8 (epithelial cells) and vimentin (fibroblasts) as appropriate. All of the data were consistent with enhanced AR protein turnover.

Extraction of total cell RNA and analysis of steady-state mRNA levels (Fig. 2d) indicated that the decrease in AR protein was not due to inhibition of transcription of the $\mathrm{AR}$ genes or a decrease in mRNA stability in the various cell types, as observed after primary culture of most prostate cells in vitro. At all stages, the loads of transfected plasmid DNA and transfection efficiencies were also carefully controlled and although the density/ growth rates of the cell cultures affected the magnitude of the result in terms of overall signal, the AR degradative effect was identical.

\section{Intracellular localisation of AR gene products}

Both the normal (PNT1 and pf1SV1) transfected cells and the LNCaP cells were stained with an
anti-AR monoclonal antibody (Clone 2F12 from Novocastra) in the presence and absence of both androgens and Casodex. As shown in Fig. 3, all AR-positive cell types cultured in the absence of androgens (R10dcc) stained strongly for cytoplasmic AR (Fig. 3a,e, i), although the staining intensity was considerably greater in the wild-type AR-transfected cells (Fig. 3e, i). On addition of the potent androgen DHT, the pattern of staining changed dramatically as the wild-type AR translocated to the cell nucleus (Fig. $3 f, j$ ), whereas pancellular staining, only partly localised to the nucleus, was observed in LNCaP (Fig. 3b). After treatment with Casodex, the pattern again altered: with wild-type AR (Fig. $3 g, k$ ), the nuclear localisation of the receptor was confined to a punctate although still intense stain, which decreased over a $6-\mathrm{h}$ treatment period. Also, after $6 \mathrm{~h}$ of treatment with Casodex, but not with DHT, the discrete architectural integrity of the cell nuclei in the AR-transfected cells was beginning to break down. Conversely, there was no similar nuclear punctate pattern observed in the overall staining of the LNCaP cells, although the stain did become rapidly more diffuse as the duration of the Casodex treatment period increased (Fig. $3 c$ ). As shown by the duplicate cultures stained with the phenotyping vimentin and cytokeratin antibodies, at this point there was no detectable change in overall cell morphology.

\section{Detection of cell death in AR-transfected cells}

To confirm that the AR-transfected cells and the $\mathrm{LNCaP}$ cells were responding to the addition of Casodex, AR-transfected cells were Casodextreated for $6 \mathrm{~h}$, followed by addition of the fluorescent dye DAPI (see Materials and Methods). Viable growing cells exclude the DAPI from their nuclei, whereas apoptotic or inviable cells accumulate DAPI, resulting in strong blue fluorescence when the still-living cultures are observed by inverted fluorescence microscopy under ultraviolet illumination. Measurements of cell viability in living cultures by addition of DAPI to the medium readily detects both apoptotic and necrotic cells, as show in Fig. $4 a$ in which the arrowed (panel A, red fluorescent) apoptotic cells, detected by AnnexinV binding) in an overgrown LNCaP culture, are already counterstained with DAPI (panel B, blue fluorescence).

The DAPI fluorescence patterns shown in Fig. $4 b$ confirm that only the AR-transfected PNT1A and LNCaP cultures (panels B and D), and not PNT1A transfected either with CAT (panels A and C) or an 
AR antisense construct (not shown) take up DAPI after Casodex treatment. Note that only a proportion of the AR-transfected PNT1A cells showed evidence of DAPI uptake (equivalent to the transfected proportion), whereas all the $\mathrm{LNCaP}$ cells were DAPI permeable after $6 \mathrm{~h}$ of Casodex treatment, even without transfection of the recombinant wild-type AR. There was some evidence that a proportion of $\mathrm{LNCaP}$ cells within the individual colonies displayed a more rapid response to the Casodex treatment. As this was observed only in the pCEP4.AR transfected cells, it is most likely that these cells corresponded to those in which the $\mathrm{AR}_{877}$ mutant had been supplemented with the more Casodex-responsive wild-type AR from pCEP4.AR. This is shown in more detail in panels $\mathrm{E}$ and $\mathrm{F}$ of Fig. $4 b$ in which the combined phase/fluorescence picture of AR-transfected PNT1A and LNCaP cells, after $2 \mathrm{~h}$ of treatment with Casodex, reveals a subset of strongly DAPIpermeable cells. Untransfected PNT1A cells or untreated PNT1A and LNCaP cells produced images identical to those in panels $\mathrm{A}$ and $\mathrm{C}$ of Fig. $4 b$, showing an average spontaneous cell death rate (probably a result of apoptosis) of less than $1 \%$, as previously shown by Berthon et al. (1995).

\section{DISCUSSION}

By using both immortalised prostate epithelial cells (PNT1A) and fibroblasts (pf1SV1) derived from normal tissue, efficiently transfected with a wildtype AR gene, we have demonstrated distinct mechanistic differences in the $\mathrm{AR}$ response to a major non-steroidal antiandrogen Casodex, when compared with the $\mathrm{AR}_{877}$ mutant in the hormone dependent LNCap tumour cell line. Although the Casodex-mediated enhanced AR turnover was present in all prostate cell types transfected with wild-type $A R$, the intracellular location and nature of this response was different from that in the widely used $\mathrm{LNCaP}$ cell line. This is clearly shown in Fig. 3, in which the diffuse nature of the AR immunostain in both DHT and Casodex-treated $\mathrm{LNCaP}$ cells and the apparent failure of most of the mutant $\mathrm{AR}_{877}$ to translocate to the nucleus are in direct contrast to the results obtained with the wild-type AR-transfected cells, in which the intracellular localisation and trafficking of the wild-type $A R$ in response to the natural substrate DHT is consistent with the proposed mechanism of steroid action.

Cytoplasmic HSPs are normally complexed with $\mathrm{AR}$ in the absence of androgens such as DHT. Both wild-type and the $\mathrm{AR}_{877}$ mutant in $\mathrm{LNCaP}$ are

www.endocrinology.org capable of binding HSPs, but the addition of Casodex, unlike addition of DHT, is less able to release the mutant AR from HSP sequestration (Veldscholdte et al. 1992b, Kallio et al. 1994), leading to impaired nuclear translocation. Casodextreated LNCaP cells are therefore unable to transactivate AR-responsive genes, as the receptor is not correctly targeted to the AR-responsive genes. However, as the $\mathrm{AR}_{877}$ is nevertheless degraded, the protease(s) responsible for turnover of transfected $\mathrm{AR}$, as for other proteins such as $\beta$-galactosidase, are probably present in both the nuclear and cytoplasmic compartments (Zhou et al. 1995, Tsuneoka \& Mekada 1992). Zhou et al. (1995) used a series of site directed mutant ARs expressed in COS cells and elegantly showed that neither nuclear localisation nor dimerisation influenced AR degradation.

Antagonist-induced degradation of steroid receptors is not, however, a novel observation. Two antioestrogens - ICI 164,384 and ICI 182,780 have been shown to reduce intracellular oestrogen receptor (ER) content by inhibiting receptor dimerisation (Fawell et al. 1990), destroying nucleo-cytoplasmic shuttling of ER (Dauvois et al. 1993) and increasing receptor turnover (Dauvois et al. 1992). ICI 182,780 induced a punctate staining pattern, similar to that observed in our AR-transfected prostate cells, in the nuclei of COS-1 cells transfected with a wild-type ER. Loss of ER protein expression in vivo after treatment with ICI 182,780 has also been documented previously (McClelland et al. 1996). The mechanism was explained in more detail by exploiting a novel oestrogen-independent cell line MCF-7:2A, which expresses both a functional wild-type ER and a mutant ER that can no longer bind ligands (Pink \& Jordan 1996). Treatment of MCF-7:2A with ICI 182,780 caused a rapid loss of only the wild-type ER protein. Interestingly, as autoregulation of the endogenous wild-type ER transcript was lifted, ER mRNA actually increased, which was reflected in an accumulation of mutant ER protein over the following 2 days (Pink \& Jordan 1996). No such upregulation of transcription of the wild-type $A R$ was observed in the transient expression model.

Examination of the structures of the various ligands (Fig. 1) reveals that, whereas ICI 182,780 closely resembles oestrogen, Casodex is apparently different from the natural ligand DHT. This may explain the observation that Casodex is capable of targeting for degradation both wild-type AR and the mutant $\mathrm{AR}_{877}$. In contrast, to date only wild-type ER has been shown to be degraded by ICI 164,384 and ICI 182,780 treatment (Dauvois et al. 1992, McClelland et al. 1996). The AR model 


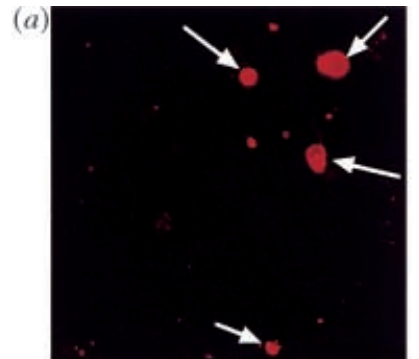

A

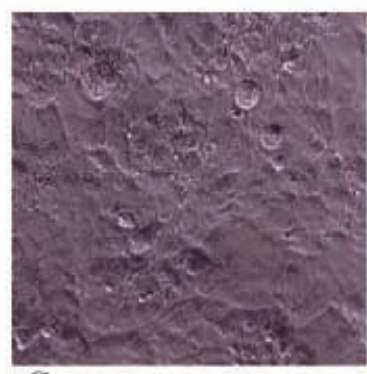

C

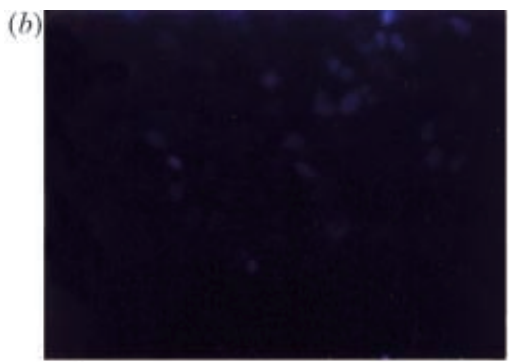

A

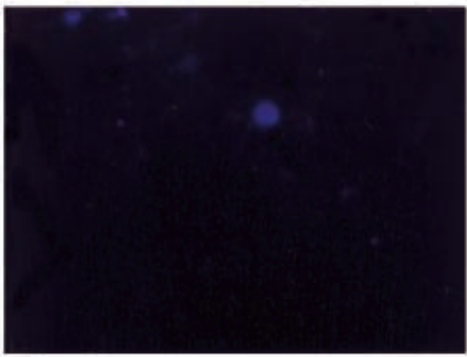

C

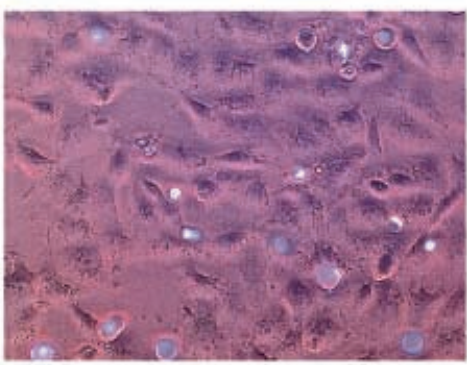

E

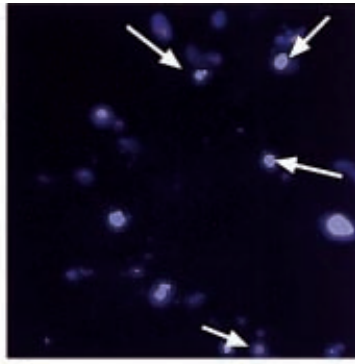

B

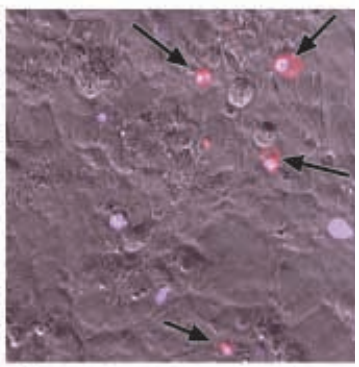

D

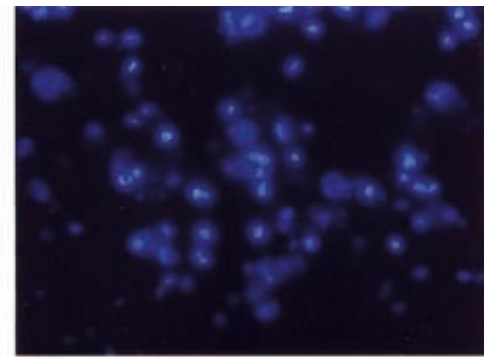

B

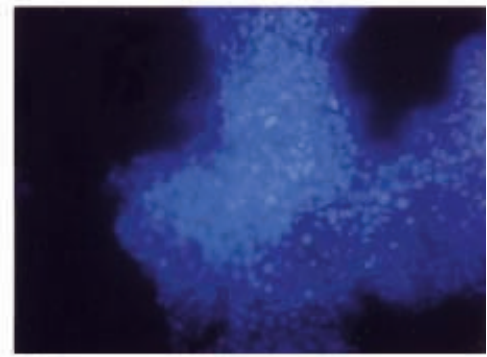

D

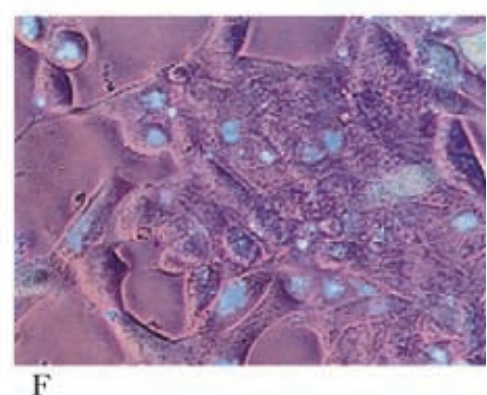

FIGURE 4. 
reported here is the currently the most representative in vitro model available for the prostatic response to antisteroid receptor agents.

Antiandrogens currently offer an effective treatment for hormone-responsive prostate cancer, particularly against disseminated disease. The development of androgen-independent disease is inevitably fatal. While the simple inhibition of AR function may provide a ready explanation for the effectiveness of Casodex, the mechanism appears to be more complex and positive in its effects on cells in the prostate. Involution of the prostate (of both normal and tumour phenotype) is a rapid event the mechanism of which has been studied to some extent in vivo and in vitro (Isaacs et al. 1994, Westin et al. 1993, 1995). The variations in nuclear morphology seen in Fig. 3 after Casodex treatment are reminiscent of the initial stages of apoptosis, which we have already shown can occur in the untransfected immortalised cell model (Berthon et al. 1995). A chemical model of apoptosis in $\mathrm{LNCaP}$ using lovastatin has implicated a caspase cascade (Marcelli et al. 1998), but androgen deprivation models have proven more difficult to reproduce in the $\mathrm{LNCaP}$ cell line, in which maintenance in stripped medium initiates but does not complete the apoptotic program (Saeed et al. 1997).

The cell death observed after Casodex treatment (Fig. 4) confirms that the downstream pathways for the antiandrogen response are intact in the immortalised prostate cells, but also indicates that the active pathway is distinct from the apoptotic pathways potently inhibited by the immortalising SV40 large $\mathrm{T}$ antigen.

Loss of androgen sensitivity in prostate tumours is believed to arise partly by mutation of the AR gene (Culig et al. 1993a,b, Suzuki et al. 1993, Gaddipati et al. 1994, Elo et al. 1995, Taplin et al. 1995, Visakorpi et al. 1995, Yeh \& Chang 1996, Koivisto et al. 1998), although only a few tumour cell line studies have been published (Visakorpi et al. 1995, Koivisto et al. 1998). Unlike some other antiandrogens, Casodex is clearly able to inhibit the growth of both wild-type and mutant $\mathrm{AR}_{877^{-}}$ containing cells, and targets the degradation of the $\mathrm{AR}$ in both types of cell. Other antiandrogens may also induce degradation of wild-type $A R$ and induce the same conformational changes, but Casodex has been shown to induce a different conformational change in $\mathrm{AR}_{877}$ in vitro compared with the related compound hydroxyflutamide (Kuil \& Mulder 1994, 1995, Kallio et al. 1994). Our data confirm that addition of hydroxyflutamide does not stabilise the wild-type AR to the same extent as DHT and does not induce AR turnover with the same kinetics as Casodex (Fig. 2).

Interestingly, attempts to develop a stable constitutive wild-type AR expression model in prostate have not been successful, as these cells have undergone deletion or mutation of the transgene in the small minority of surviving lines (AS Waller and NJ Maitland, unpublished observations). Several normal breast epithelial cell lines show the same effect after transfer of an exogenous ER cDNA (Zajchowski et al. 1993), and reduced growth rates after AR transfection into androgen-independent prostate cancer cell lines such as PC3 have been reported (Yuan et al. 1993). Efficient and biologically relevant expression of wild-type or various mutant ARs in the transient system reported here should nevertheless permit mechanistic studies of the response in the human prostate to both native androgens and a variety of inhibitors, with the aim of a more refined treatment for prostate cancer, and an understanding of its molecular basis.

\section{ACKNOWLEDGEMENTS}

This study was funded by a project grant to PHB and NJM from the Yorkshire Cancer Research, and carried out in partial fulfilment of DPhil studies (AW). We wish also to thank Peter Crosby and Meg Stark for photographic assistance, Lucy

FIGURE 4. Use of DAPI stain to detect Casodex-induced toxicity in AR-transfected cells. (a) Specificity of DAPI staining to detect inviable cells in cell culture. The panels show LNCaP cells grown to high density and stained with DAPI in the culture medium without permeabilisation (blue fluorescence in panel B). The cultures were then washed briefly and stained with AnnexinV (see Materials and Methods) to detect apoptotic cells (red fluorescence in panel A). (C) Phase image of the cells. (D) Combined image in which the co-localisation of the intact apoptotic cells and a subset of the DAPI permeable cells (indicated by the arrows) is shown. (b) DAPI stain of AR- and CAT-transfected PNT1A and LNCaP cells. Subconfluent monolayers of PNT1A (panels A, B, E) and LNCaP (panels C, D, F) cells were transfected with pCEP4.CAT (panels A,C) or pCEP4.AR (panels B, D, E and F) plasmids. After 24 h, $10^{-6}$ M Casodex was added to the confluent monolayers of PNT1A cells shown in panels A and B, and $10^{-6}$ M DHT to cells shown in panel $\mathrm{E}$. The LNCaP cells (which grew as multilayered colonies) shown in panels $\mathrm{C}$ and $\mathrm{F}$ received $10^{-6} \mathrm{M}$ DHT and cells shown in panel D $10^{-6}$ M Casodex. Two hours (panels E and F) or 6 h (panels A-D) after addition of steroid, DAPI stain (see Materials and Methods) was added to the culture medium and fluorescent images were captured at $250 \times$ magnification (panels A-D) and $400 \times$ (panels E, F) 15 min later. 
Hopwood and Cath Ramsay for technical assistance and Jo Birch for secretarial work and collecting and organising references. Thanks also to Dr B J A Furr, AstraZeneca, for his reading of the manuscript and for providing Casodex.

\section{REFERENCES}

Berthon P, Cussenot O, Hopwood L, Le Duc A \& Maitland N J 1995 Functional expression of SV40 in normal human prostatic epithelial and fibroblastic cells: differentiation pattern of non-tumorigenic cell lines. International Fournal of Oncology 6 333-343.

Culig Z, Hobisch A, Cronauer MV, Cato ACB, Hittmair A, Radmayr C, Eberle J, Bartsch G \& Klocker H 1993 a Mutant androgen receptor detected in an advanced-stage prostatic carcinoma is activated by adrenal androgens and progesterone. Molecular Endocrinology 7 1541-1550.

Culig Z, Klocker H, Eberle J, Kaspar F, Hobisch A, Cronauer MV \& Bartsch G $1993 b$ DNA sequence of the androgen receptor in prostatic tumor cell lines and tissue specimens assessed by means of the polymerase chain reaction. Prostate 22 11-22.

Cussenot O, Berthon P, Faille A, Berger R, Mowszowicz I, Teillac P, LeDuc A \& Calvo F 1991 Immortalization of human adult normal prostatic epithelial cells by liposomes containing SV40. Fournal of Urology 143 881-886.

Dauvois S, Danielian PS, White R \& Parker MG 1992 Antiestrogen ICI 164,384 reduces cellular estrogen receptor content by increasing its turnover. Proceedings of the National Academy of Sciences of the USA 89 4037-4041.

Dauvois S, White R \& Parker MG 1993 The antiestrogen ICI 182780 disrupts estrogen receptor nucleocytoplasmic shuttling. Fournal of Cell Science 106 1377-1388.

Elo JP, Kvist L, Leinonen K, Isomaa V, Henttu P, Lukkarinen O \& Vihko P 1995 Mutated human androgen receptor gene detected in a prostatic cancer patient is also activated by estradiol. Fournal of Clinical Endocrinology and Metabolism 80 3494-3500.

Fawell SE, White R, Hoare S, Sydenham M, Page M \& Parker MG 1990 Inhibition of estrogen receptor-DNA binding by the 'pure' antiestrogen ICI 164,384 appears to be mediated by impaired receptor dimerization. Proceedings of the National Academy of Sciences of the USA 87 6883-6887.

Gaddipati JP, McLeod DG, Heidenberg HB, Sesterhenn IA, Finger MJ, Moul JW \& Srivastava S 1994 Frequent detection of codon 877 mutation in the androgen receptor gene in advanced prostate cancers. Cancer Research $\mathbf{5 4}$ 2861-2864.

Hayward SW, Dahiya R, Cunha GR, Bartek J, Deshpande N \& Narayan P 1995 Establishment and characterization of an immortalized but non-transformed human prostate epithelial cell line: BPH-1. In Vitro Cellular and Developmental Biology 31 14-24.

Isaacs JT, Furuya Y \& Berges R 1994 The role of androgen in the regulation of programmed cell death/apoptosis in normal and malignant prostatic tissue. Seminars in Cancer Biology $\mathbf{5}$ 391-400.

Kallio PJ, Jänne OA \& Palvimo JJ 1994 Agonists, but not antagonists, alter the conformation of the hormone-binding domain of androgen receptor. Endocrinology 134 998-1001.

Koivisto P, Kolmer M, Visakorpi T \& Kallioniemi OP 1998 Androgen receptor gene and hormonal therapy failure of prostate cancer. American Fournal of Pathology 152 1-9.

Kozak M 1989 The scanning model for translation; an update. Fournal of Cell Biology 108 229-241.
Kuil CW \& Mulder E 1994 Mechanism of antiandrogen action: conformational changes of the receptor. Molecular and Cellular Endocrinology 102 R1-R5.

Kuil CW \& Mulder E 1995 Effects of androgens and antiandrogens on the conformation of the androgen receptor. Annals of the New York Academy of Sciences 761 351-354.

Kuil CW, Berrevoets CA \& Mulder E 1995 Ligand-induced conformational alterations of the androgen receptor analyzed by limited trypsinization: studies on the mechanism of antiandrogen action. Fournal of Biological Chemistry $\mathbf{2 7 0}$ 27569-27576.

Kuiper GGJM \& Brinkmann AO 1995 Phosphotryptic peptide analysis of the human androgen receptor: detection of a hormone-induced phosphopeptide. Biochemistry 34 1851-1857.

Laemmli EK 1970 The cleavage of structural proteins during assembly of the head of bacteriophage T4. Nature 227 680-685.

McClelland RA, Gee JMW, Francis AB, Robertson JFR, Blamey RW, Wakelin, AE \& Nicholson RI 1996 Short-term effects of pure anti-oestrogen ICI 182780 treatment on oestrogen receptor, epidermal growth factor receptor and transforming growth factor-alpha protein expression in human breast cancer. European Fournal of Cancer 32A 413-416.

Marcelli M, Cunningham GR, Haidacher SJ, Padayatty SJ, Sturgis L, Kagan C \& Denner L 1998 Caspase 7 is activated during lovastatin induced apoptosis of the prostate cancer cell line LNCaP. Cancer Research 58 76-83.

Montie JE 1996 A glimpse at the future of some endocrine aspects of prostate cancer. Prostate 6 57-61.

Pink JJ \& Jordan VC 1996 Models of estrogen receptor regulation by estrogens and antiestrogens in breast cancer cell lines. Cancer Research 56 2321-2330.

Prostate Cancer Trialists' Collaborative Group 1996 Maximum androgen blockade in advanced prostate cancer: an overview of 22 randomised trials with 3283 deaths in 5710 patients. Lancet 346 265-269.

Ruokonen M, Shan JD, Hedberg P, Patrikainen L \& Vihko P 1996 Transfecting well-differentiated prostatic cancer cell line LNCaP. Biochemical and Biophysical Research Communications 218 794-796.

Saeed B, Zhang H \& Ng S-C 1997 Apoptotic program is initiated but not completed in $\mathrm{LNCaP}$ cells in response to growth in charcoal-stripped media. Prostate 31 145-152.

Schuurmans ALG, Bolt J, Veldscholte J \& Mulder E 1991 Regulation of growth of $\mathrm{LNCaP}$ human prostate tumor cells by growth factors and steroid hormones. Fournal of Steroid Biochemistry and Molecular Biology 40 193-197.

Sultan C, Lumbroso S, Poujol N, Belon C, Boudon C \& Lobaccaro J-M 1993 Mutations of androgen receptor gene in androgen insensitivity syndromes. Fournal of Steroid Biochemistry and Molecular Biology 46 519-530.

Suzuki H, Sato N, Watabe Y, Masai M, Seino S \& Shimazaki J 1993 Androgen receptor gene mutations in human prostate cancer. Fournal of Steroid Biochemistry and Molecular Biology $46759-765$

Taplin M-E, Bubley GJ, Shuster TD, Frantz ME, Spooner AE, Ogata GK, Keer HN \& Balk SP 1995 Mutation of the androgen-receptor gene in metastatic androgen-independent prostate cancer. New England Fournal of Medicine 332 1393-1398.

Teutsch G, Goubet F, Battman T, Bonfils A, Bouchoux F, Cerede E, Gofflo D, Gaillard-Kelly M \& Philibert D 1994 Non-steroidal antiandrogens: synthesis and biological profile of high-affinity ligands for the androgen receptor. Fournal of Steroid Biochemistry and Molecular Biology 48 111-119. 
Tsuneoka M \& Mekada E 1992 Degradation of a nuclear localised protein in mammalian COS cells using Escherichia coli 66 galactosidase as a model protein. Fournal of Biological Chemistry 267 9107-9111.

Veldscholte J, Ris-Stalpers C, Kuiper GGJM, Berrevoets C, Claasen E, van Rooij HCJ, Trapman J, Brinkmann AO \& Mulder E 1990 A mutation in the ligand binding domain of the androgen receptor of human $\mathrm{LNCaP}$ cells affects steroid binding characteristics and reponse to anti-androgens. Biochemical and Biophysical Research Communications 173 534-540.

Veldscholte J, Berrevoets CA, Brinkmann AO, Grootegoed JA \& Mulder E 1992a Anti-androgens and the mutated androgen receptor of $\mathrm{LNCaP}$ cells: differential effects on binding affinity, heat-shock protein interaction, and transcription activation. Biochemistry 31 2393-2399.

Veldscholte J, Berrevoets CA, Zegers ND, van der Kwast TH, Grootegoed JA \& Mulder E $1992 b$ Hormone-induced dissociation of the androgen receptor-heat-shock protein complex: use of a new monoclonal antibody to distinguish transformed from nontransformed receptors. Biochemistry 31 7422-7430.

Veldscholte J, Berrevoets CA \& Mulder E 1994 Studies on the human prostatic cancer cell line LNCaP. Fournal of Steroid Biochemistry and Molecular Biology 49 341-346.

Vermes I, Haanen C, Steffensnakken H \& Reutelingsperger C 1995 A novel assay for apoptosis - flow cytomeric detection of phosphatidylserine expression on early apoptotic cells using fluorescein-labeled annexin V. Fournal of Immunological Methods 184 39-51.

Visakorpi T, Hyytinen E, Koivisto P, Tanner M, Keinänen R, Palmberg C, Palotie A, Tammela T, Isola J \& Kallioniemi O-P 1995 in vivo amplification of the androgen receptor gene and progression of human prostate cancer. Nature Genetics 9 401-406.

Waller A 1998 The expression of androgen receptor protein in an in vitro model of prostate epithelial and stromal cells. DPhil Thesis. University of York.
Westin P, Bergh A \& Damber J-E 1993 Castration rapidly results in a major reduction in epithelial cell numbers in the rat prostate, but not in the highly differentiated Dunning R3327 prostatic adenocarcinoma. Prostate 22 65-74.

Westin P, Stattin P, Damber J-E \& Bergh A 1995 Castration therapy rapidly induces apoptosis in a minority and decreases cell proliferation in a majority of human prostatic tumors. American Fournal of Pathology 146 $1368-1375$.

Wong C, Zhou Z, Sar M \& Wilson EM 1993 Steroid requirement for androgen receptor dimerization and DNA binding. Modulation by intramolecular interactions between the $\mathrm{NH}_{2}$-terminal and steroid-binding domains. Fournal of Biological Chemistry 268 19004-19012.

Yeh S \& Chang C 1996 Cloning and characterization of a specific coactivator, $\mathrm{ARA}_{70}$, for the androgen receptor in human prostate cells. Proceedings of the National Academy of Sciences of the USA 93 5517-5521.

Yuan S, Trachtenberg J, Mills GB, Brown TJ, Xu F \& Keating A 1993 Androgen-induced inhibition of cell proliferation in an androgen-insensitive prostate cancer cell line (PC-3) transfected with a human androgen receptor complementary DNA. Cancer Research $\mathbf{5 3}$ 1304-1311.

Zajchowski DA, Sager R \& Webster L 1993 Estrogen inhibits the growth of estrogen receptor-negative, but not estrogen receptor-positive, human mammary epithelial cells expressing a recombinant estrogen receptor. Cancer Research 53 5004-5011.

Zhou Z-X, Lane MV, Kemppainen JA, French FS \& Wilson EM 1995 Specificity of ligand dependent androgen receptor stabilisation: receptor domain interactions influence ligand dissociation and receptor stability. Molecular Endocrinology 9 208-218.

RECEIVED 16 December 1999 